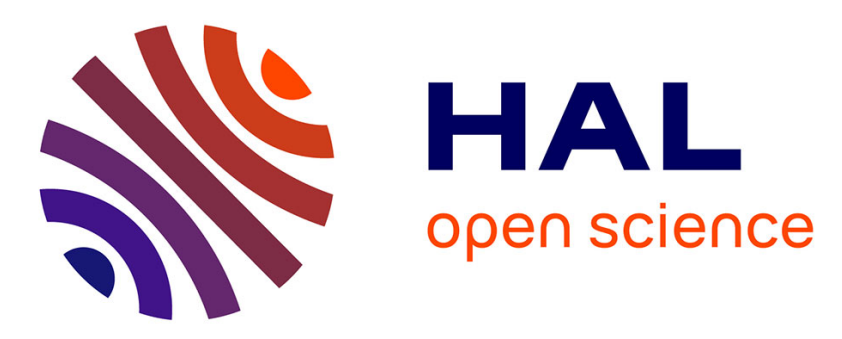

\title{
Impact of human papillomavirus vaccination on anal cancer incidence in French women.
}

\author{
Laureen Ribassin-Majed, Rachid Lounes, Stéphan Clémençon
}

\section{To cite this version:}

Laureen Ribassin-Majed, Rachid Lounes, Stéphan Clémençon. Impact of human papillomavirus vaccination on anal cancer incidence in French women.. Journal of Public Health and Epidemiology, 2012, 4 (5), pp.141-149. 10.5897/JPHE11.199 . hal-00702699

\section{HAL Id: hal-00702699 \\ https://hal.science/hal-00702699}

Submitted on 31 May 2012

HAL is a multi-disciplinary open access archive for the deposit and dissemination of scientific research documents, whether they are published or not. The documents may come from teaching and research institutions in France or abroad, or from public or private research centers.
L'archive ouverte pluridisciplinaire HAL, est destinée au dépôt et à la diffusion de documents scientifiques de niveau recherche, publiés ou non, émanant des établissements d'enseignement et de recherche français ou étrangers, des laboratoires publics ou privés. 


\title{
Impact of human papillomavirus vaccination on anal cancer incidence in French women
}

\author{
L. Ribassin-Majed ${ }^{1 \star}$, R. Lounes ${ }^{1}$ and S. Clémençon ${ }^{2}$ \\ ${ }^{1}$ Laboratoire Mathématiques Appliquées à Paris 5 (MAP 5) UMR CNRS 8145, Université Paris Descartes, Sorbonne \\ Paris Cité, France. \\ ${ }^{2}$ LTCI Telecom ParisTech/CNRS No. 5141, Paris, France.
}

Accepted 8 March, 2012

\begin{abstract}
Human papillomavirus (HPV) 16 and 18 are found to be involved in $80 \%$ of anal cancers. Two vaccines against HPV infections are currently available, and vaccination policies aim to decrease mainly, incidence of cervical cancers. Moreover, an impact of HPV vaccination on the incidence of anal cancer can also be expected. Our aim was to assess the potential benefits of HPV vaccination on the occurrence of female anal cancer in France. We developed a dynamic model for the heterosexual transmission of HPV and its progression to anal cancer in women. The model was calibrated using French data of anal cancer incidence. Considering vaccine coverage observed at the launch of vaccination campaign in France, reductions of 55 and $85 \%$ in the incidence of anal cancers due to HPV 16/18 are to be expected in French women 30 and 50 years after vaccine introduction, respectively. In case of a significant decrease in vaccine coverage, a dramatic reduction in the impact of HPV vaccination on female anal cancers would be observed. The number of anal cancer cases in French women is therefore expected to decrease significantly in $\mathbf{3 0}$ years, assuming sustained HPV vaccine coverage.
\end{abstract}

Key words: Dynamic model, human papillomavirus, vaccine, anal cancer.

\section{INTRODUCTION}

Several western countries have recently developed vaccination policies against human papillomavirus (HPV) to prevent cervical cancer in women. It is expected that prevention against HPV can also dramatically decrease the risk of other male and female anogenital cancers. Therefore, the impact of HPV vaccination on non-cervical cancers must now be assessed. Some studies have considered non-cervical cancers including anal cancer (Elbasha and Dasbach, 2010; Jit et al., 2011). While epidemiological data of female anogenital non-cervical cancers remain sparse, some papers have reported on anal cancer incidence and its economic burden in France. For instance, the economic costs of anal cancer are close to that of cervical cancer, despite a lower

\footnotetext{
${ }^{*}$ Corresponding author. E-mail: laureen.majed@parisdescartes.fr. Tel : 33 (0)1 83945869. Fax: 33(0)1 42864144.
}

incidence (Abramowitz et al., 2010b). In 2006, 2500 females with anal cancer were treated in French hospitals (Abramowitz et al., 2010b). The incidence of anal cancer is higher in women than in men; the French regional registers of cancers have published incidence rates varying from 0.2 to 0.7 per 100,000 in men and from 0.7 to 1.7 per 100,000 in women (IARC, 2007). An increase in anal cancer incidence has been reported in the past decades in Denmark, Scotland and Australia (Brewster and Bhatti, 2006; Jin et al., 2011; Nielsen et al., 2011). As with cervical cancer, epidemiological studies have established a causal relationship between human papillomavirus (HPV) infections and occurrence of anal cancer (Castor et al., 2011). HPV 16 and/or 18 are related to approximately $80 \%$ of anal cancers (Franceschi and De Vuyst, 2009; Abramowitz et al., 2010a).

Vaccination against HPV infections aims to decrease cervical cancer incidence and may reduce the occurrence of other cancers due to HPV infections (anogenital cancers and head and neck cancers). Two prophylactic 
vaccines against HPV infections are available in France and have been found to be highly effective in women who have never been infected with HPV (Paavonen et al., 2009; Munoz et al., 2009). The quadrivalent vaccine protects against HPV 6/11, which are responsible for genital warts, and against HPV 16/18, which are associated with $70 \%$ of cervical cancers. The bivalent vaccine protects against HPV $16 / 18$ infection. The efficacy of the bivalent vaccine against anal HPV 16/18 infection has been found to be similar to vaccine efficacy against cervical HPV 16/18 infection in young women (Kreimer et al., 2011). The quadrivalent vaccine was found to be efficacious in prevention of anogenital lesions associated with HPV 16/18 in Men who have Sex with Men (MSM) (Giuliano et al., 2011) and in heterosexual men (Hillman et al., 2011). Thus a decrease in anal cancers due to HPV $16 / 18$ could be expected after the initiation of HPV vaccination.

In France, the permanent Vaccines Advisory Committees ("Comité technique des vaccinations" and "Conseil supérieur d'hygiène publique de France") recommend vaccinating 14-year old females. Moreover, a catch-up program has been offered to women aged from 15 to 23 . Females eligible for the catch-up program either have not been sexually active yet or may report a first sexual relationship that occurred in the year prior to vaccination (Haute Autorité de Santé).

As anal cancers usually occur several decades after HPV infections, in France $75 \%$ of anal cancers are diagnosed in individuals aged more than 65 years (Fédération Nationale des Centres de Lutte Contre le Cancer, 1992), mathematical models are useful to assess any expected reductions in cancer cases. In these models, vaccine coverage in young women is taken into account.

Various dynamic models have been published to assess the potential impact of HPV vaccination in several countries focusing on cervical cancer (Dasbach et al., 2006). A cost-effectiveness evaluation has been done in France using a Markov model (Bergeron et al., 2008). Markov model do not take into account herd immunity effect. Another paper assessed the impact of HPV vaccination on cervical cancers in French women using a dynamic model (Ribassin-Majed et al., 2012). To estimate the cost-effectiveness of vaccination policies, other cancers due to HPV may be considered. In the US, the cost-effectiveness of HPV vaccination in Men who have Sex with Men (MSM) has been estimated considering anal cancers (Kim, 2010). Elbasha et al. (2007, 2010) developed several dynamic models to assess the economic impact of quadrivalent vaccine in the USA including a specific model for anal cancer (Elbasha and Dasbach, 2010). Jit et al. (2011) compared the effect and cost-effectiveness of bivalent and quadrivalent vaccines in UK considering a model of HPV transmission, progression to anal cancers was taken into account. To our knowledge, no dynamic model assessed specifically the impact of HPV vaccination on anal cancers in French females.

We estimated the potential impact of vaccination on the reduction of anal cancer incidence in French women. In this paper, we present a deterministic model for the heterosexual transmission of HPV and its progression to anal cancer in women. Several scenarios of vaccination were considered. Sensitivity analyses were conducted for all scenarios in order to assess the impact of vaccination considering variations in vaccine efficacy. We aimed to provide useful data to assess expected reductions of anal cancer incidence after vaccine introduction in France.

\section{METHODOLOGY}

\section{Dynamic model structure}

We used Scilab-5.1.1 software (http://www.scilab.org/fr) to design a deterministic model for heterosexual transmission of oncogenic HPV types 16 and 18. HPV types 16 and 18 are included in both vaccines (bivalent and quadrivalent). In our modeling, they are modeled jointly. We developed a system of 784 ordinary differential equations. We set the population size in the model to 100,000 individuals, equally divided into females and males. The epidemiologic model simulated heterosexual transmission of HPV$16 / 18$ infections in males and females, and progression to anal cancer for females. Modeled natural history included compartments of precursor lesions of anal cancer AIN I, AIN II/III (Figure 1). After clearance of HPV 16/18 infection, infected individuals go back to susceptible compartments.

We assumed that individuals entered the sexually active population at 14 years old. This assumption was consistent with the sexual comportment of French population, $0.4 \%$ of women and $2.4 \%$ of men have had sexual intercourse before the age of 14 years old in 2006 (Bajos et al., 2008). Fourteen-year-old persons entered the model at a gender-specific and sexual activity-specific rate. Sexually active women could be infected with HPV 16/18 in the anal region if they had had sexual intercourse with men who were HPV infected in the anogenital region. HPV infections are transmitted by contact between mucosal in the anogenital region; we assumed that all sexual intercourse (anal or vaginal) between an infected man and a susceptible woman could induce HPV infection in female anal region. In fact, women are probably also infected in cervical region, potential synergy between anal and cervical infections have been studied (Goodman et al., 2010).

Individuals exited the model at death (age and gender specific using French data) or when they reached the age of 84 . The heterosexually mixing population was divided into 14 age groups ([14 to 19], [20 to 24], [25 to 29], [30 to 34], [35 to 39], [40 to 44], [45 to 49], [50 to 54], [55 to 59], [60 to 64], [65 to 69], [70 to 74], [75 to 79 ], [80 to 84]). We developed a demographic model (Hethcote, 1997; Elbasha et al., 2007) which simulated the distribution of the French population. Details on the demographic model are described in Ribassin-Majed et al. (2012). Annual transition rates into age groups were defined by the demographic model.

Each age group was divided into 4 levels of sexual behavior. The level of sexual activity was defined by the number of sexual partners in the last 12 months ( 0 sexual partners-including nonsexually-active individuals-, 1 partner, between 2 and 3 partners and 4 partners or more in last year). Results from the French survey on sexual behavior were used to derive the distribution between groups of sexual behavior (Table A1, Appendix). Mixing between sexual activity groups was quantified by the mixing matrix as 


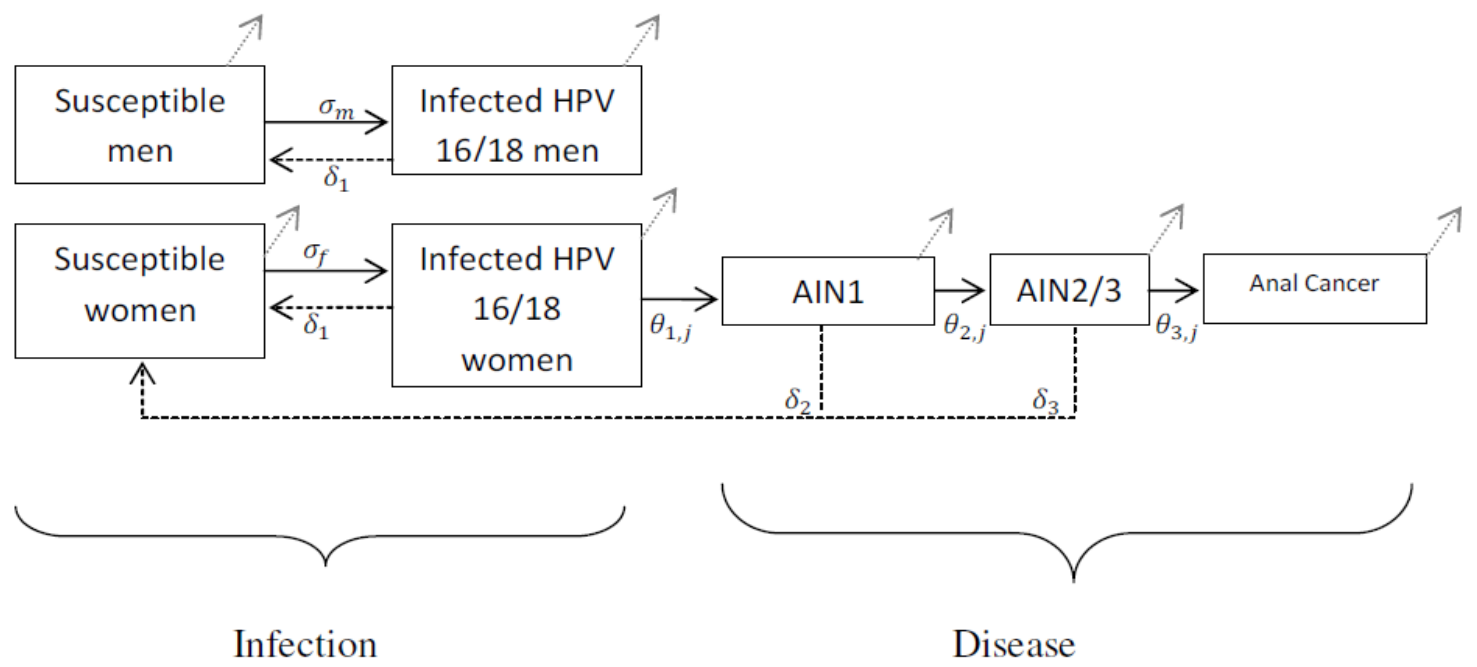

Figure 1. Flow diagram. Schematic representation of the dynamic model compartments corresponding to one age-group $i(i=1 \ldots 14)$ and one group of sexual activity $I(i=1 \ldots 4)$ in non-vaccinated population.

described by Garnett and Anderson (1993), details in Appendix. The parameter $\varepsilon$ described the degree of mixing between sexual activity groups which may vary from fully assortative ( $\varepsilon=0$, when individuals have sexual partners in the same sexual activity class) to fully random ( $\varepsilon=1$ ). Mixing between sexual activity groups was assumed to be preferentially assortative ( $\varepsilon=0.4)$.

\section{Risk of infection}

The risk of infection by gender depends on: probabilities of transmission from an infected individual to a susceptible one $\left(\sigma_{f}\right.$ and $\left.\sigma_{m}\right)$; the number of sex partners in last 12 months $\left(c_{l}=\right.$ $0,1,2$ and $3, \geq 4)$; the proportion of infected individuals in the pool of sexual partners according to their age-group and level of sexual behavior. We developed a mixing matrix $\rho_{g, i, k}$ appropriate for the sexually active population in France, which gives the proportion of individuals of gender $g$, in age-group $i$ who have sexual partners in age-group $k$ (Table A2, Appendix).

\section{Transmission model data}

In a fitting procedure, we derived the probabilities of HPV $16 / 18$ transmission per partnership (from an infected individual to a susceptible one) for both sexes, the clearance rate (the same in males and females) and age-specific progression rates to AIN1, AIN $2 / 3$ and anal cancer. To assess the probabilities of HPV transmission and the clearance rate, our criteria of best fitting was: the model reproduced HPV 16/18 female and male prevalence within $10 \%$. As French data for male prevalence are not available, we used data from USA in both sexes in order to consider transmission of infection between the same population (Hernandez et al., 2005; Nielson et al., 2009). Several sets of the 3 parameters $(200,000)$, probabilities of transmission in males, females and clearance rate, were tested. To assess age-specific rates for progression of the disease, we fit the model on female age-specific anal cancer incidence (IARC, 2007). As HPV types 16 and 18 are responsible for $80 \%$ of anal cancer (Abramowitz et al., 2010a), we multiplied the published French incidence rate of anal cancer by 0.8 to assess the incidence rate of anal cancer due to HPV types 16 and 18 (in French women).

Published data for regression rates from AIN 1 and AIN 2/3 compartments to susceptible compartments were used (Palefsky et al., 1998).

\section{Vaccine characteristics}

We divided the population into vaccinated and unvaccinated categories. Individuals entered the model at 14 years old (being vaccinated or not) in susceptible compartments. Individuals in the youngest age groups ([14 to 19] and [20 to 24]) could be vaccinated after entrance into the model in accordance with the French vaccine program and then moved to vaccinated categories. We considered several vaccination scenarios. Immunity from the vaccine was assumed to be sustained lifelong and vaccine efficacy was assumed to be $90 \%$ in the base case. Thus, vaccinated individuals could experiment breakthrough HPV infections and may progress to disease (anal cancer in females). Efficacy of $90 \%$ means that vaccination avoids $90 \%$ of HPV infections in vaccinated individuals compared to non-vaccinated individuals.

\section{Vaccination scenarios}

First, we studied the vaccine coverage observed in France at the beginning of the vaccination campaign in 2007 to assess vaccine efficacy (scenario 1). Then, we assessed vaccine efficacy in different hypothetical situations; in scenario 2 , we considered a lower vaccine coverage, as observed in France a few years after the initiation of the vaccination campaign (Fagot et al., 2011). Finally, in the last scenario (scenario 3), we considered a very pessimistic vaccine coverage.

In the scenarios considered, vaccine coverage was assumed to be constant in time. We considered only individuals who received the 3 doses of vaccine. In the first scenario, coverage of vaccination (using 3 doses of vaccines) was set to that observed in France in 2007 (Fagot et al., 2011): $30 \%$ of women aged 14 to 19 and $10 \%$ of women aged 20 to 24 (Table 1). Please note that these vaccine coverages are annual rates in the model (e.g. each year, $30 \%$ of women aged 14 to 19 years receive the 3 doses of vaccine), the corresponding cumulative rates for scenario 1 are presented in 
Table 1. Scenarios of vaccination considered in simulations. Vaccine coverages are annual rates.

\begin{tabular}{cccc}
\hline Vaccine coverage for women & Scenario 1 (\%) & Scenario 2 (\%) & Scenario 3 (\%) \\
\hline $14-19$ & $30^{*}$ & 20 & 5 \\
$20-24$ & 10 & 10 & 5 \\
\hline
\end{tabular}

${ }^{*}$ E.g.: each year, $30 \%$ of women in the age-group [14 to 19] receive the 3 doses of vaccine.

\section{Cumulative vaccine coverages in scenario 1}

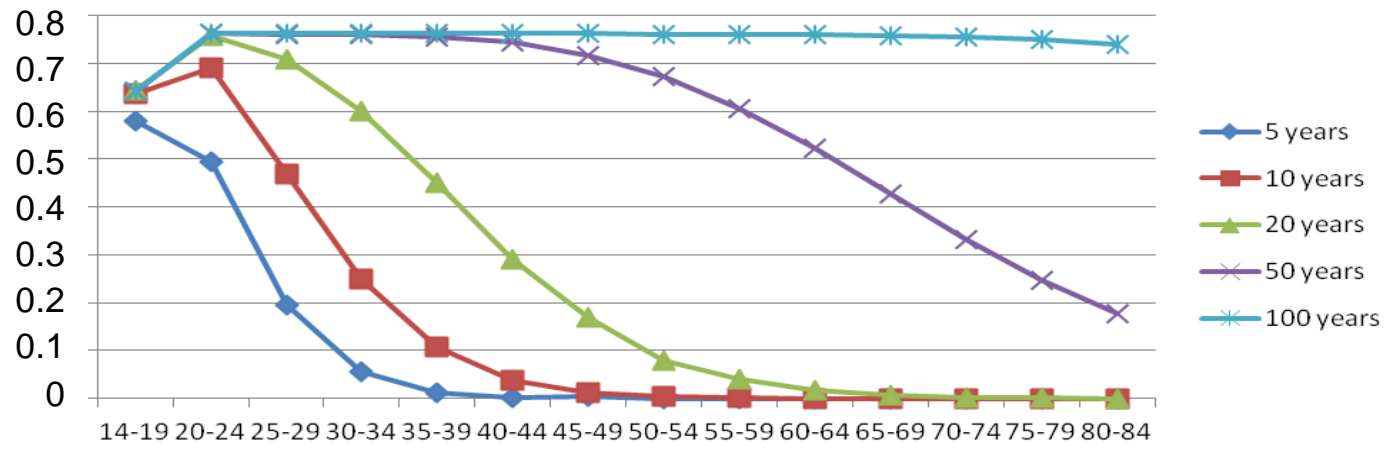

Figure 2. Cumulative vaccine coverages in scenario 1: 5, 10, 20,50 and 100 years after introduction of vaccination assuming constant vaccine coverage.

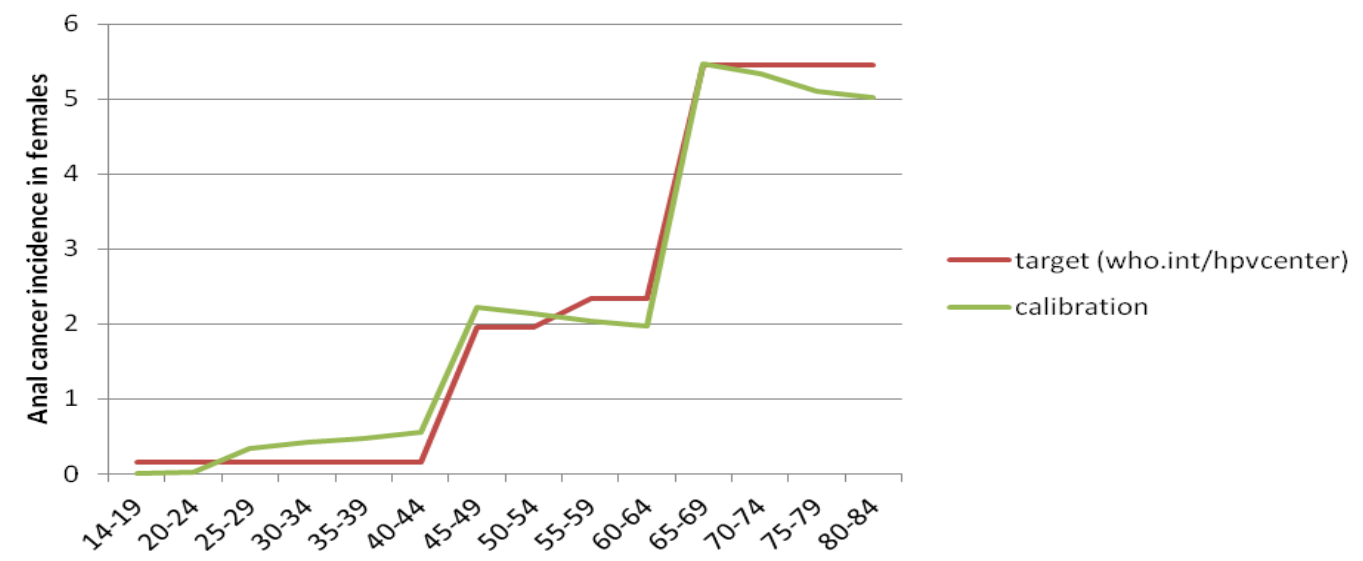

Figure 3. Anal cancer incidence in females estimated in calibration step (model without vaccination) (number of new cases of female anal cancer per 100,000 women).

Figure 2. For instance, a few years after vaccination launch, almost $60 \%$ of women aged 14 to 19 years could be vaccinated ( 3 doses), assuming constant vaccine coverage (Figure 2). In the second scenario, we considered a lower vaccine coverage in women: $20 \%$ of women aged 14 to 19 and $10 \%$ of women age 20 to 24 as observed a few years after initiation of vaccination (Fagot et al., $2011)$. In the last scenario, only $5 \%$ of women aged 14 to 24 were completely vaccinated (with 3 doses of vaccine).

\section{Model validation}

To validate the model, we considered the epidemiological data before vaccination introduction and compared it with the steadystate estimates of the deterministic model for non-vaccinated individuals. Probabilities of transmission of HPV 16/18 (from an infected individual to a susceptible one) have been estimated in our fitting procedure to 0.21 (female) and 0.16 (male) and the clearance rate has been estimated to 0.83 .

Among infected females, the rates of progression to anal cancer were estimated for each age-group. We compared the age-specific incidence of anal cancer predicted by the model with published data (Human Papillomavirus and Related Cancers in France; Summary Report, 2010; available at who.int/hpvcenter). Each age-specific incidence rate of anal cancer predicted by the model was similar to the age-specific incidence rate of anal cancer due to HPV 16/18 in France within a precision of $10 \%$ (Figure 3 ). 
Table 2. Anal prevalence of HPV 16/18 in women in each scenario: 20, 30 and 50 years after initiation of vaccination $(\mathrm{t}=0)$. Vaccine coverage was supposed constant in each scenario. Percentage of reduction in HPV prevalence compared to the case without vaccination.

\begin{tabular}{lccc}
\hline Anal prevalence of HPV 16/18 for women & $\mathbf{2 0}$ years (\%) & 30 years (\%) & $\mathbf{5 0}$ years (\%) \\
\hline Scenario 1 & -58 & -75 & -91 \\
Scenario 2 & -53 & -70 & -86 \\
Scenario 3 & -29 & -42 & -58 \\
\hline
\end{tabular}

Table 3. Prevalence of HPV 16/18 in men in anogenital site in each scenario: 20, 30 and 50 years after initiation of vaccination $(t=0)$. Vaccine coverage was supposed constant in each scenario. Percentage of reduction in HPV prevalence compared to the case without vaccination.

\begin{tabular}{lccc}
\hline Prevalence of HPV $\mathbf{1 6 / 1 8}$ for men & 20 years (\%) & 30 years (\%) & 50 years (\%) \\
\hline Scenario 1 & -52 & -69 & -87 \\
Scenario 2 & -47 & -64 & -82 \\
Scenario 3 & -24 & -37 & -52 \\
\hline
\end{tabular}

\section{Sensitivity analysis}

Sensitivity analyses were conducted to assess the effect of parameter variations on model results. Although, vaccine efficacy was initially set to $90 \%$, we set vaccine efficacy in sensitivity analyses to 60 and $40 \%$. Thus, we studied the impact of vaccination on HPV prevalence and anal cancer incidence using low (60 and $40 \%$ ) vaccine efficacies. Another sensitivity analysis corresponding to a variation in the sexual mixing parameter is described elsewhere (Ribassin-Majed et al., 2012).

\section{RESULTS}

\section{HPV infection prevalence}

Both vaccination strategies considered in scenarios 1 and 2 led to a sizeable decrease in HPV prevalence in the anal region among females 20,30 and 50 years after vaccination introduction (Table 2). At the horizon of 20 years after launch of vaccination, reductions in anal HPV prevalence (females) of 58 and $53 \%$ will be expected considering respectively scenario 1 and 2 . Five decades after introduction of vaccination, anal HPV 16/18 prevalence in females could be approximately divided by 10 in both scenarios 1 and 2 .

The deterministic model that we developed takes into account the reduction of male HPV 16/18 prevalence in the anogenital region due to female vaccination. Table 3 shows the expected reduction in male prevalence for each scenario.

\section{Anal cancer in females}

In the base-case analysis, we assumed a $90 \%$ efficacy for the vaccines. In scenario 1 which considers the vaccine coverage observed in France at the initiation of the vaccination campaign, a $55 \%$ reduction of anal cancer incidence in females due to HPV 16/18 may be expected 30 years after the introduction of the vaccine. Scenario 1 predicted a $85 \%$ reduction of anal cancer cases due to HPV 16/18 50 years after vaccination launch, assuming constant vaccine coverage (Table 4 and Figure 4).

In scenario 2, which considers a lower vaccination coverage (20 and 10\% respectively in women aged 14 to 19 and 20 to 24), 50 and $80 \%$ reductions in the numbers of new anal cancers would be expected respectively 30 and 50 years after vaccine introduction.

Considering the pessimistic scenario in which $5 \%$ of females aged 14 to 24 years were vaccinated (scenario 3 ), a $26 \%$ reduction of anal cancer incidence would be expected in a horizon of 30 years after initiation of vaccination, this reduction reached $52 \%$ in a horizon of 50 years if vaccine coverage is constant.

\section{Sensitivity analyses}

As efficacy of vaccine was initially set to $90 \%$ in the basecase, we considered the effect of lower vaccine efficacies on the incidence of anal cancer in sensitivity analyses (Table 4). A lower efficacy of vaccine $(60 \%)$ reduced the impact of vaccination on anal cancer incidence. Considering scenario 1 with an efficacy of $60 \%$, our model predicted lower reduction in anal cancer incidence compared to a $90 \%$ efficacy 50 years after introduction of the vaccine (reductions of 63 and $85 \%$, respectively). In case of an efficacy of $40 \%$, impact of vaccination would dramatically decrease. A $45 \%$ reduction of anal cancer incidence would be expected 50 years after initiation of vaccination whereas a $85 \%$ reduction would be reached with an efficacy of $90 \%$ in scenario 1 (assuming constant vaccine coverage). 
Table 4. Expected reductions in incidence of anal cancer (annual number of new cases per 100,000 individuals) due to HPV 16/18 in French women in each scenario 20,30 and 50 years after initiation of vaccination $(t=0)$ and considering efficacy of vaccine of $90 \%$ in base-case, 60 and $40 \%$ in sensitivity analyses.

\begin{tabular}{ccccc}
\hline $\begin{array}{c}\text { Time since introduction } \\
\text { of vaccination (years) }\end{array}$ & Vaccine efficacy (\%) & Scenario 1 (\%) & Scenario 2 (\%) & Scenario 3 (\%) \\
\hline \multirow{2}{*}{20} & 90 & -28 & -24 & -8 \\
& 60 & -16 & -13 & -3 \\
& 40 & -9 & -7 & -0 \\
30 & 90 & -55 & -50 & -26 \\
& 60 & -37 & -33 & -16 \\
& 40 & -24 & -22 & -10 \\
50 & 90 & -85 & -80 & -52 \\
& 60 & -63 & -59 & -35 \\
& 40 & -45 & -42 & -23 \\
\hline
\end{tabular}

Vaccine coverage was assumed constant in each scenario.

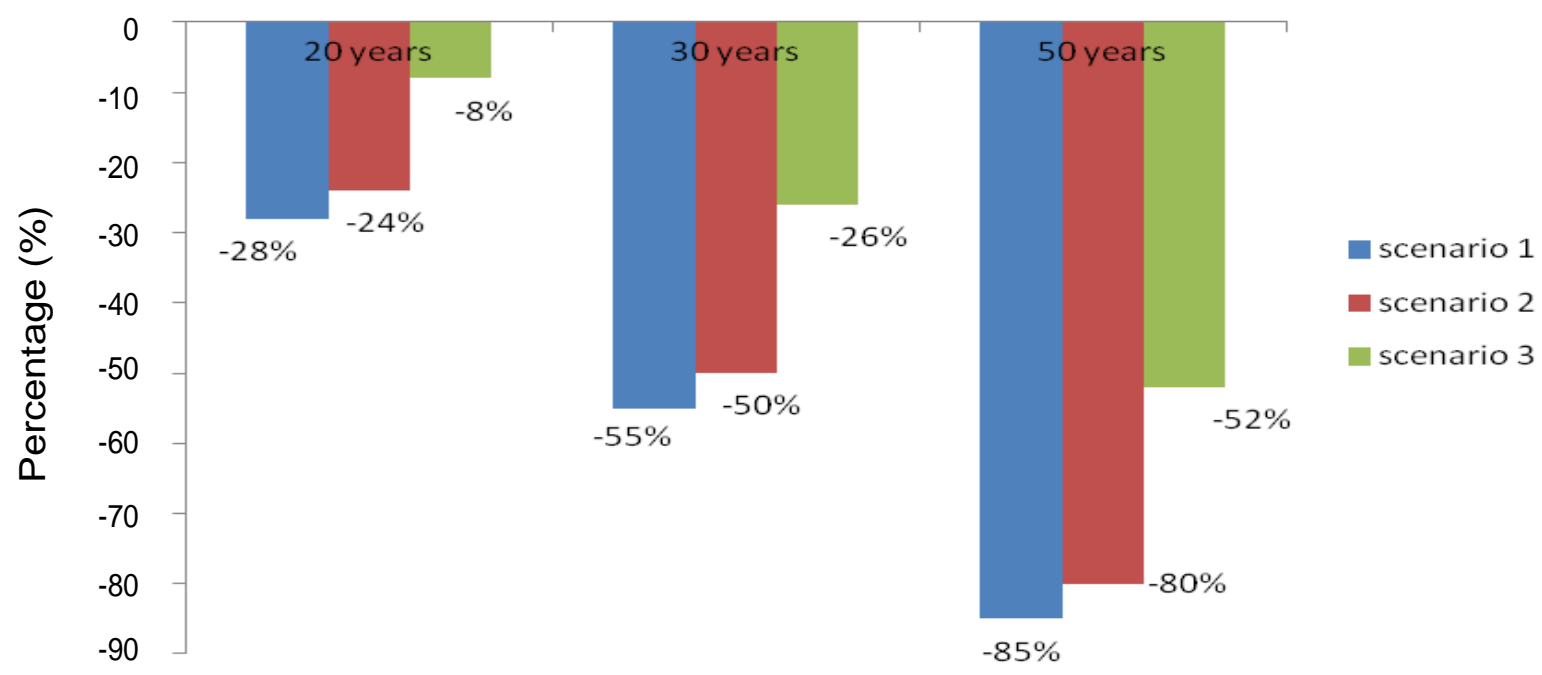

Figure 4. Expected reductions in female anal cancer incidence (due to HPV 16/18): 20, 30 and 50 years after launch of vaccination campaign in France (compared to anal cancer incidence prior to vaccination).

\section{DISCUSSION}

We have developed a dynamic model to assess the impact of HPV vaccination on the incidence of anal cancer in French women using observed coverage of vaccination. Using deterministic modeling, we have estimated the potential impact of vaccination against HPV to prevent anal cancers. Considering the vaccine coverage reached at the initiation of vaccination in France $(30 \%$ of women aged 14 to 19 years and $10 \%$ of women aged 20 to 24 years) are vaccinated every year, the incidence of anal cancer in women could be reduced by $55 \%$ in the horizon of 30 years and by $85 \%$ in the horizon of 50 years compared to anal cancer incidence prior to vaccination. We compared several scenarios of vaccination coverage. The first scenario corresponded to the vaccination coverage observed in France at the initiation of the vaccination campaign (Fagot et al., 2011). To understand the impact of vaccination, cumulative vaccine coverages have to be considered. In modeling, annual rates are used.

The second scenario corresponded to a lower vaccine coverage, as described by Fagot et al. (2011) in France a few years after the introduction of HPV vaccines. Finally, in the third scenario, we considered a very low vaccine coverage. In all scenarios, vaccine coverage in the age- 
group targeted for ongoing vaccination was assumed to be constant in time. In the base-case, we assumed a $90 \%$ efficacy of vaccine, and in the sensitivity analysis we assessed the impact of vaccination considering lower efficacies of vaccine: 60 and $40 \%$. Efficacy of HPV vaccination to prevent anal cancers in females decreased dramatically when vaccination coverage was very low. In addition to cervical cancer preclusion, HPV vaccination can also prevent anal cancer in women. Our results supports maintaining the vaccination coverage at a level no lower than that observed after vaccination introduction.

Nonetheless, our findings depend on the assumptions made in our modeling. We considered that individuals entered into the sexually active population when they are 14 years old. This assumption is consistent with the survey on the sexual behavior in France (Bajos et al., 2008). Only $0.5 \%$ of the interviewed women (aged from 18 to 69 years) declared having their first sexual intercourse before the age of 14 years.

In the deterministic model that we developed, we used a Susceptible-Infected-Susceptible (S-I-S) structure. We did not assume that individuals who cleared HPV infection developed natural immunity against HPV. This approach of natural history for HPV infections has been used in other HPV models (Myers et al., 2000; Goldie et al., 2003; Kulasingam and Myers, 2003; Sanders and Taira, 2003; Goldie et al., 2004; Taira et al., 2004; Ribassin-Majed et al., 2012), whereas some other published models assumed natural immunity against HPV using Susceptible-Infected-Removed (S-I-R) structure (Elbasha et al., 2010). Existence and length of natural immunity after HPV clearance is uncertain and not biologically proved. The way that natural history is modeled has an impact on predictions (Van de Velde et al., 2010). Dynamic models which used SIS structure predict higher effectiveness of vaccine (Van de Velde et al., 2010).

The model assumed constant vaccine coverage whereas a decrease was observed in France between 2007 and 2009. Efficacy of vaccination was assumed to last lifelong. Consequently, we did not include the need for vaccine booster shots in our model. The protective effect of vaccines is known to last at least several years and the need for boosters is currently unknown (Paavonen et al., 2009; Castellsague et al., 2011).

Using deterministic modeling, our model took into account the "herd immunity" effect corresponding to a decrease in HPV 16/18 infections and anal cancers in non-vaccinated subpopulations of females due to vaccination coverage of other individuals.

One of the strengths of our modeling is that we considered the actual vaccine coverage observed in France. In France, vaccine coverage has been reported to be low and decreasing: while $33.3 \%$ of girls aged 14 in 2007 were vaccinated with 3 doses of the vaccine, only 23.7 and $5.4 \%$ of girls aged 14 were vaccinated, respectively in 2008 and 2009 (Fagot et al., 2011).
However, cumulative rates have to be considered.

Considering scenario 1 and assuming constant vaccine coverage, at the horizon of 10 years after introduction of vaccination, more than $60 \%$ of females aged 14 to 19 years will have received the 3 doses of vaccine. Fifty years after vaccination launch, more than $70 \%$ of women aged 14 to 44 years will be vaccinated. In our modeling, vaccination rates are constant, therefore variations in vaccine coverage over the time could not be considered. The trend observed (decrease of vaccine coverage) could be balanced with an increase in a long term perspective. Controversies in HPV vaccines and others vaccines (e.g. Influenza H1N1 vaccine or Hepatitis B Vaccine) could explain the mistrust of vaccines in French individuals. Campaigns of information for the targeted population (females and their mothers) and for gynecologist and pediatricians may have an impact on the acceptance of HPV vaccination (Blödt et al., 2011; Hughes et al., 2011; Lutringer-Magnin et al., 2011).

We considered 3 vaccination scenarios and confirmed a dramatic decrease of HPV vaccination efficacy to prevent anal cancer. We assumed that only individuals who received 3 doses of vaccine were protected against HPV infection. Our modeling also considered different values regarding the efficacy of vaccines. In the basecase, we considered a high efficacy as observed in clinical trials which conducted statistical analyses in "per protocol" cohorts. The efficacy of vaccines in girls and young women who have never been infected with HPV is close to $100 \%$, whereas efficacy drops significantly in "intention to treat" analyses (full cohort) (Rambout et al., 2007; Paavonen et al., 2009; Munoz et al., 2010; Castellsague et al., 2011). We therefore considered HPV vaccination with different levels of efficacy in sensitivity analyses. In France, populations targeted by HPV vaccines are represented by girls aged 14 years while young women aged 15 to 23 years can be vaccinated in a catch-up program. We may assume that some of the targeted populations, particularly in the catch-up program, could have been infected with HPV prior to vaccination. In this case, efficacy of vaccine is expected to be lower than $100 \%$. We aimed in our paper to assess the impact of HPV vaccination in the presence of a decreased vaccination efficacy due to HPV infections prior to vaccination. For instance, Hernandez et al. (2005) observed a prevalence of anal HPV infections of $12 \%$ in young females (age 18 to 24 years old). Some countries have chosen to target younger females of 9 to 12 years old (ECCA).

In conclusion, to our knowledge, this analysis is the first to explore the potential impact of HPV vaccination on anal cancer incidence in France. The findings suggest that a $85 \%$ reduction in anal cancer incidence due to HPV 16/18 is expected in French women in the horizon of 50 years assuming sustained HPV vaccine coverage (which corresponds to a cumulative vaccine coverage of $60 \%$ in women aged 14 to 19 years a few years after vaccination launch) and full (90\%) vaccine efficacy. 


\section{ACKNOWLEDGEMENTS}

The authors would like to thank the reviewers for careful review of our manuscript and providing us comments and suggestions which improved the quality of the manuscript.

\section{REFERENCES}

Abramowitz L, Jacquard AC, Jaroud F, Haesebaert J, Siproudhis L, Pradat $\mathrm{P}$, Aynaud $\mathrm{O}$, Leocmach $\mathrm{Y}$, Soubeyrand B, Dachez R, Riethmuller D, Mougin C, Pretet JL, Denis F (2010a) Human papillomavirus genotype distribution in anal cancer in France: The Edith V study. Int. J. Cancer, 129(2): 433-439.

Abramowitz L, Remy V, Vainchtock A (2010b). Economic burden of anal cancer management in France. Rev. Epidemiol. Sante Publique, 58(5): 331-338.

Bajos N, Bozon M, Beltzer N (2008). French National Survey on sexual behavior. Book.

Bergeron C, Largeron N, Mcallister R, Mathevet P, Remy V (2008). Cost-effectiveness analysis of the introduction of a quadrivalent human papillomavirus vaccine in France. Int. J. Technol. Assess Health Care, 24(1): 10-19.

Blödt SHC, Müller-Nordhorn J, Rieckmann N (2011). Human Papillomavirus awareness, knowledge and vaccine acceptance: A survey among 18-25 year old male and female vocational school students in Berlin, Germany. Eur. J. Public Health, doi:10.1093/eurpub/ckr188.

Brewster DH, Bhatti LA (2006). Increasing incidence of squamous cell carcinoma of the anus in Scotland, 1975-2002. Br. J. Cancer, 95(1): 87-90.

Castellsague X, Munoz N, Pitisuttithum P, Ferris D, Monsonego J, Ault K, Luna J, Myers E, Mallary S, Bautista OM, Bryan J, Vuocolo S, Haupt RM, Saah A (2011). End-of-study safety, immunogenicity, and efficacy of quadrivalent HPV (types $6,11,16,18$ ) recombinant vaccine in adult women 24-45 years of age. Br. J. Cancer, 105(1): 28-37.

Castor MD, Da Silva HJ, Gondim Martins DB, De Mello RJ (2011). HPV and precancerous lesions of anal canal in women: Systematic review. Int. J. Colorectal Dis., pp. 271-276.

Dasbach EJ, Elbasha EH, Insinga RP (2006). Mathematical models for predicting the epidemiologic and economic impact of vaccination against human papillomavirus infection and disease. Epidemiol. Rev., 28: 88-100.

ECCA European Cervical Cancer Association. HPV vaccination accross Europe. http://www.ecca.info/fr/ecca-publications.html.

Elbasha EH, Dasbach EJ (2010). Impact of vaccinating boys and men against HPV in the United States. Vaccine, 28(42): 6858-6867.

Elbasha EH, Dasbach EJ, Insinga RP (2007). Model for assessing human papillomavirus vaccination strategies. Emerg. Infect. Dis., 13(1): 28-41.

Fagot JP, Boutrelle A, Ricordeau P, Weill A, Allemand H (2011). HPV vaccination in France: uptake, costs and issues for the National Health Insurance. Vaccine, 29(19): 3610-3616.

National Federation of Centers for Cancer (1992). Permanent cancer Survey 1976-1989: Long-term survival of patients treated for cancer

Franceschi S, De Vuyst H (2009). Human papillomavirus vaccines and anal carcinoma. Curr. Opin. HIV AIDS, 4(1): 57-63.

Garnett GP, Anderson RM (1993). Contact tracing and the estimation of

sexual mixing patterns: the epidemiology of gonococcal infections. Sex Transm. Dis., 20(4): 181-191.

Giuliano AR, Palefsky JM, Goldstone S, Moreira ED Jr., Penny ME, Aranda $\mathrm{C}$, Vardas $\mathrm{E}$, Moi $\mathrm{H}$, Jessen $\mathrm{H}$, Hillman R, Chang $\mathrm{YH}$, Ferris D, Rouleau D, Bryan J, Marshall JB, Vuocolo S, Barr E, Radley D, Haupt RM, Guris D (2011). Efficacy of quadrivalent HPV vaccine against HPV Infection and disease in males. N. Engl. J. Med., 364(5): 401-411.

Goldie SJ, Grima D, Kohli M, Wright TC, Weinstein M, Franco E (2003). A comprehensive natural history model of HPV infection and cervical cancer to estimate the clinical impact of a prophylactic HPV-16/18 vaccine. Int. J. Cancer, 106(6): 896-904.

Goldie SJ, Kohli M, Grima D, Weinstein MC, Wright TC, Bosch FX, Franco E (2004). Projected clinical benefits and cost-effectiveness of a human papillomavirus 16/18 vaccine. J. Natl. Cancer Inst., 96(8): 604-615.

Goodman MTKM, Hernandez BY, Wilkens XZLR, Thompson PJ, Killeen J, Lori Kamemoto AYBS (2010). The Influence of Multiple Human Papillomavirus Types on the Risk of Genotype-Concordant Incident Infections of the Anus and Cervix: The Hawaii HPV Cohort Study. J Infect. Dis., p. 335.

Haute Autorite De Sante "http://www.has-sante.fr/portail/upload/docs/application/pdf/ct-4029 gardasil.pdf," in.

Hernandez BY, Mcduffie K, Zhu X, Wilkens LR, Killeen J, Kessel B, Wakabayashi MT, Bertram CC, Easa D, Ning L, Boyd J, Sunoo C, Kamemoto L, Goodman MT (2005). Anal human papillomavirus infection in women and its relationship with cervical infection. Cancer Epidemiol. Biomarkers Prev., 14(11 Pt 1): 2550-2556.

Hethcote HW (1997). An age-structured model for pertussis transmission. Math Biosci., 145(2): 89-136.

Hillman RJ, Giuliano AR, Palefsky JM, Goldstone S, Moreira ED, Vardas Jr E, Aranda C, Jessen H, Ferris DG, Coutlee F, Marshall JB, Vuocolo S, Haupt RM, Guris D, Garner EI (2011). Immunogenicity of the quadrivalent human papillomavirus (type 6/11/16/18) vaccine in males 16 to 26 years old. Clin. Vaccine Immunol., 19(2): 261-267.

Hughes CC, Jones AL, Feemster KA, Fiks AG (2011). HPV vaccine decision making in pediatric primary care: $A$ semi-structured interview study. BMC Pediatr., 11: 74.

IARC (2007). "Cancer incidence in five continents. Vol. IX," in.

Jin F, Stein AN, Conway EL, Regan DG, Law M, Brotherton JM, Hocking J, Grulich AE (2011). Trends in anal cancer in Australia, 1982-2005. Vaccine, 29(12): 2322-2327.

Jit M, Chapman R, Hughes O, Choi YH (2011). Comparing bivalent and quadrivalent human papillomavirus vaccines: Economic evaluation based on transmission model. BMJ, 343, d5775.

Kim JJ (2010). Targeted human papillomavirus vaccination of men who have sex with men in the USA: A cost-effectiveness modelling analysis. Lancet. Infect. Dis., 10(12): 845-852.

Kreimer AR, Gonzalez P, Katki HA, Porras C, Schiffman M, Rodriguez AC, Solomon D, Jimenez S, Schiller JT, Lowy DR, Van Doorn LJ, Struijk L, Quint W, Chen S, Wacholder S, Hildesheim A, Herrero R (2011). Efficacy of a bivalent HPV $16 / 18$ vaccine against anal HPV 16/18 infection among young women: A nested analysis within the Costa Rica Vaccine Trial. Lancet. Oncol., 12(9): 862-870.

Kulasingam SL, Myers ER (2003). Potential health and economic impact of adding a human papillomavirus vaccine to screening programs. JAMA, 290(6): 781-789.

Lutringer-Magnin DKJ, Barone $\mathrm{G}$, Borne $\mathrm{H}$, Regnier V, Vanhems $\mathrm{P}$, Chauvin F, Lasset C (2011). [Gynaecologists' attitudes and practices towards HPV vaccination: a quantitative-qualitative study in RhôneAlpes]. Gynecol. Obstet. Fertil., 39(12): 687-693.

Muñoz N, Manalastas Jr, R, Pitisuttithum P, Tresukosol D, Monsonego J, Ault K, Clavel C, Luna J, Myers E, Hood S, Bautista O, Bryan J, Taddeo FJ, Esser MT, Vuocolo S, Haupt RM, Barr E, Saah A (2009). Safety, immunogenicity, and efficacy of quadrivalent human papillomavirus (types $6,11,16,18$ ) recombinant vaccine in women aged 24-45 years: A randomised, double-blind trial. Lancet, National Institute of Cancer, Bogotá, Colombia. nubia.munoz@free.fr, 373: 1949-1957.

Myers ER, Mccrory DC, Nanda K, Bastian L, Matchar DB (2000). Mathematical model for the natural history of human papillomavirus infection and cervical carcinogenesis. Am. J. Epidemiol., 151(12): 1158-1171.

Nielsen A, Munk C, Kjaer SK (2011). Trends in incidence of anal cancer and high-grade anal intraepithelial neoplasia in Denmark, 1978-2008. Int. J. Cancer, 130(5): 1168-1173.

Nielson CM, Harris RB, Flores R, Abrahamsen M, Papenfuss MR, Dunne EF, Markowitz LE, Giuliano AR (2009). Multiple-type human papillomavirus infection in male anogenital sites: Prevalence and associated factors. Cancer Epidemiol. Biomarkers Prev., 18(4): 10771083.

Paavonen J, Naud P, Salmeron J, Wheeler CM, Chow SN, Apter D, 
Kitchener H, Castellsague X, Teixeira JC, Skinner SR, Hedrick J, Jaisamrarn U, Limson G, Garland S, Szarewski A, Romanowski B, Aoki FY, Schwarz TF, Poppe WA, Bosch FX, Jenkins D, Hardt K, Zahaf T, Descamps D, Struyf F, Lehtinen M, Dubin G (2009). Efficacy of human papillomavirus (HPV)-16/18 AS04-adjuvanted vaccine against cervical infection and precancer caused by oncogenic HPV types (PATRICIA): Final analysis of a double-blind, randomised study in young women. Lancet, 374(9686): 301-314.

Palefsky JM, Holly EA, Hogeboom CJ, Ralston ML, Dacosta MM, Botts R, Berry JM, Jay N, Darragh TM (1998). Virologic, immunologic, and clinical parameters in the incidence and progression of anal squamous intraepithelial lesions in HIV-positive and HIV-negative homosexual men. J. Acquir. Immune Defic. Syndr. Hum. Retrovirol., 17(4): 314-319.

Rambout L, Hopkins L, Hutton B, Fergusson D (2007). Prophylactic vaccination against human papillomavirus infection and disease in women: a systematic review of randomized controlled trials. CMAJ, 177(5): 469-479.

Ribassin-Majed L, Lounes R, Clemencon S (2012). Efficacy of vaccination against HPV infections to prevent cervical cancer in France: Present assessment and pathways to improve vaccination policies. PLoS ONE 7(3): e32251. doi:10.1371/journal.pone.0032251.
Sanders GD, Taira AV (2003). Cost-effectiveness of a potential vaccine for human papillomavirus. Emerg. Infect. Dis., 9(1): 37-48.

Taira AV, Neukermans CP, Sanders GD (2004). Evaluating human papillomavirus vaccination programs. Emerg. Infect. Dis., 10(11): 1915-1923.

Van De Velde N, Brisson M, Boily MC (2010). Understanding differences in predictions of HPV vaccine effectiveness: A comparative model-based analysis. Vaccine, 28(33): 5473-5484. 


\section{APPENDIX}

Table A1. Distribution in the model in the 4 sexual-activity groups.

\begin{tabular}{lcccccccc}
\hline \multirow{2}{*}{ Group of sexual behavior } & \multicolumn{4}{c}{ Female } & \multicolumn{3}{c}{ Male } \\
\cline { 2 - 9 } & $\mathbf{0}(\%)$ & $\mathbf{1}(\%)$ & $\mathbf{2 - 3}(\%)$ & $\mathbf{2 4}(\%)$ & $\mathbf{0}(\%)$ & $\mathbf{1}(\%)$ & $\mathbf{2 - 3}(\%)$ & $\mathbf{2 4}(\%)$ \\
\hline Distribution & 15 & $75^{*}$ & 9 & 1 & 15 & 75 & 9 & 1 \\
\hline
\end{tabular}

E.g. ${ }^{*} 75 \%$ of women declared having one sexual partner in last 12 months.

Table A2. Mixing matrix between age-group. Proportion of individuals who have sexual contact with partners in youngest agegroup $(<)$, the same age-group (=) or older age group (>). e.g. ${ }^{\star} 56 \%$ of women in [20 to 24$]$ age-group have contact with men of the same age-group.

\begin{tabular}{|c|c|c|c|c|c|c|}
\hline \multirow{2}{*}{ Age group } & \multicolumn{3}{|c|}{$\%$ Female } & \multicolumn{3}{|c|}{$\%$ Male } \\
\hline & $<$ & $\rho_{f, s, t}$ & $>$ & $<$ & $\rho_{m, s, t}$ & $>$ \\
\hline 14 to 19 & to & 35 & 65 & to & 86 & 14 \\
\hline 20 to 24 & 5 & $56^{*}$ & 39 & 25 & 62 & 13 \\
\hline 25 to 29 & 7 & 46 & 47 & 38 & 46 & 16 \\
\hline 30 to 34 & 8 & 46 & 46 & 42 & 44 & 14 \\
\hline 35 to 39 & 15 & 41 & 44 & 45 & 40 & 15 \\
\hline 40 to 44 & 16 & 44 & 40 & 46 & 44 & 10 \\
\hline 45 to 49 & 16 & 39 & 45 & 50 & 35 & 15 \\
\hline 50 to 54 & 13 & 42 & 45 & 45 & 41 & 14 \\
\hline 55 to 59 & 19 & 42 & 39 & 46 & 46 & 8 \\
\hline 60 to 64 & 22 & 40 & 38 & 56 & 50 & 7 \\
\hline 65 to 69 & 17 & 47 & 36 & 53 & 39 & 8 \\
\hline 70 to 74 & 17 & 47 & 36 & 53 & 39 & 8 \\
\hline 75 to 79 & 17 & 47 & 36 & 53 & 39 & 8 \\
\hline 80 to 84 & 17 & 83 & & 53 & 47 & to \\
\hline
\end{tabular}

Mixing between sexual activity groups was quantified by the mixing matrix as described by Garnett and Anderson (1993). The probability for someone from the sexual-behavior group / to form a partnership with someone from the sexual-behavior group o is defined by:

$$
w_{l o}=\varepsilon \frac{N_{o} C_{o}}{\sum_{s=1}^{4} N_{s} C_{s}}+(1-\varepsilon) \delta_{l o}
$$

with $N_{o}$ being the proportion of individuals in sexual-activity group $o, c_{o}$ representing the average number of annual partners in group $0, \delta_{l o}$ is the Kronecker delta $\left(\delta_{l o}=1\right.$ if $I=0$ and $\delta_{l o}=0$ if $I \neq 0$ ), the parameter $\varepsilon$ described the degree of mixing between sexual activity groups which may vary from fully assortative ( $\varepsilon=0$, when individuals have sexual partners in the same sexual activity class) to fully random $(\varepsilon=1)$. Mixing between sexual activity groups was assumed to be preferentially assortative $(\varepsilon=0.4)$. 